Article

\title{
Imaginary Numbers of Climate Change Migrants?
}

\author{
Ilan Kelman 1,2 (D) \\ 1 Institute for Global Health and Institute for Risk and Disaster Reduction, University College London, \\ London WC1E 6BT, UK; ilan_kelman@hotmail.com \\ 2 University of Agder, 4630 Kristiansand, Norway
}

Received: 19 February 2019; Accepted: 23 April 2019; Published: 27 April 2019

\begin{abstract}
Within the extensive scientific and policy discussions about climate change migrants, detailed analyses continue to highlight the lack of evidence thus far for climate change directly causing migration. To understand better how climate change might or might not lead to migration, this paper explores possibilities for developing a robust, repeatable, and verifiable method to count or calculate the number of people migrating or not migrating due to climate change. The discussion starts by examining definitions of "climate change" and "migration", then looking at how to determine numbers of climate change migrants based on those definitions. These points lead to descriptions of the subjectivity and arbitrariness of the decisions needed for counting or calculating climate change migrants and non-migrants. While the scientific study of working out numbers of climate change migrants and non-migrants is challenging and interesting, especially due to its complexity, changing baselines alongside legitimate concerns about necessary assumptions lead to questions regarding the usefulness of the calculations for policy and action. Ultimately, labelling, counting, and calculating climate change migrants and non-migrants depend on political choices, so any numbers reached might not be scientifically robust. Improved understanding of people's motivations for migrating and not migrating under different circumstances, including under climate change and perceptions thereof, would be preferable to a starting point assuming that climate change inevitably causes migration.
\end{abstract}

Keywords: climate change; climigration; environmental change; migration; mobility; refugees

\section{Introduction}

Extensive scientific and policy discussions persist regarding climate change migrants and variations of the term such as "climate refugees", "climate change refugees", and "environmental migrants" (Felli and Castree 2012 in their apt critique of Foresight 2011; Gemenne 2011; Hall 2013; Leckie 2014; Manrique et al. 2018; Rakova et al. 2009). Detailed analyses continue to highlight (i) the lack of evidence linking climate change directly to migration through linear causality and (ii) the multitude of factors influencing any connections between the two (Baldwin et al. 2014; Bettini 2013; Brzoska and Fröhlich 2016; Hartmann 2010; Klepp 2017; Nicholson 2014; Watts et al. 2018a, 2018b). These critiques do not necessarily preclude ongoing interactions between climate change and migration alongside the possibility of future occurrences of large-scale migration linked to climate change.

Consequently, the question remains regarding how climate change might connect to or cause migration; that is, attribution must be ascertained. Attribution means determining that people are moving because climate change causes the migration. As another dimension of attribution, it would be important to investigate if people are forced not to migrate due to climate change when they would otherwise want to move.

Nicholson (2014) challenges the need to focus on causality, using climate change and migration to illustrate how "causality can prove a blind alley for substantive research when we become mired in trying to distil certainty from what are, in truth, irredeemably equivocal categories" (p. 159). The same 
difficulties could be raised regarding the drive to quantify climate change and migration links by asking, and trying to answer, how many climate change migrants exist and how many there could be in the future under different scenarios. Is it worthwhile trying to count? What would a calculation method be? How meaningful would the numbers be? Would the answers to these questions be different from scientific, policy, or political perspectives?

A major consequence is that providing numbers of climate change migrants or projections thereof could create tangibility whether or not the numbers are credible-and irrespective of limitations in the method(s). That is, quantifying might bypass the criticisms of, and the large uncertainties surrounding, the notion of climate change causing migration (as discussed by Baldwin et al. 2014; Bettini 2013; Brzoska and Fröhlich 2016; Hartmann 2010; Klepp 2017; Nicholson 2014) because quantitative science is often assumed to have robustness without accounting for inevitable and implicit biases in calculations (Martin 1979). For example, World Bank (2018) estimated numbers of forced migrants displaced inside their country of origin by climate change until 2050. This report's arbitrary definitions and limitations in the calculation method are described for Bangladesh by Abubakar et al. (2018), most notably how the projected environmental changes are not necessarily attributable to climate change. Rather than counting for the sake of counting to confer unsubstantiated credibility, if an accepted method could be developed for determining the numbers of climate change migrants, then many criticisms of climate change and migration links could possibly be overcome. An evidence basis for policy and action on climate change migration would therefore exist.

This paper explores possibilities for developing a robust, repeatable, and verifiable method to count and calculate the numbers of people migrating or not migrating due to climate change impacts. The discussion starts by examining definitions of "climate change" and "migration", then looking at how to count and calculate numbers based on those definitions. These points lead to descriptions of and conclusions regarding the subjectivity and arbitrariness of making necessary decisions for determining climate change migrants and non-migrants. In the end, calculation methods at the moment do not seem to be able to provide a usable evidence basis for policy or action.

\section{Background}

This section defines the two baseline concepts linked by this paper: population movement encompassing migration, mobilities, and refugees (Section 2.1) and climate change plus its impacts (Section 2.2). Defining the connectors and connections between the two is then set out (Section 2.3).

\subsection{Population Movement}

Human migration and mobilities research has long offered two truisms with respect to human population movements:

1. Mobile, sedentary, and mixed lifestyles are and always have been part of humanity (Fiddian-Qasmiyeh et al. 2016; Meir 1986; Urry 2007).

2. Many factors, including climate-related ones, influence and have always influenced human migration and non-migration decisions and forced actions (Felli and Castree 2012; Fröhlich 2017; Ritchey 1976; Stojanov 2014).

The word "migrant" generally implies movement with some level of voluntariness, as in "cases where the decision to migrate is taken freely by the individual concerned, for reasons of 'personal convenience' and without intervention of an external compelling factor" (UN Commission on Human Rights 1998, p. 9). Hence, the potential exists for "forced migrants" where there is "an external compelling factor", so a decision to move is not taken freely. Here, "forced migrant" is defined as a subset of "migrant" where "some level of voluntariness" is zero.

An immediate definitional dilemma appears: What is the distance which someone must move in order to be termed a migrant? Moving ten meters is not far, yet sometimes shifts across an international border within the same residential block or to the opposite side of the street. This situation occurs along 
parts of the France-Monaco border, e.g., Avenue d'Alsace, and along parts of the Belgium-Netherlands border, e.g., the adjoining cities of Baarle-Nassau (Netherlands) and Baarle-Hertog (Belgium).

In other places, moving ten meters could mean leaving the expected floodplain under climate change projections several decades into the future. Pingelap is an atoll within the Federated States of Micronesia in the Pacific. Some parts of the atoll are higher than $15 \mathrm{~m}$ above sea level, but all the atoll's land sits within $300 \mathrm{~m}$ of the ocean. In theory, the inhabitants could redesign and rebuild their community on the higher parts of their atoll to avoid expected sea-level rise impacts, meaning that no one would move especially far. They would do so because climate change is expected to force them to move to new locations within their atoll, so they are climate change forced migrants, yet they remain living in Pingelap, near their original homes. Rather than moving inland, buildings in the new floodplain or tidal zone could instead be raised above the new sea level. Multi-story buildings could be constructed with their ground floors opened up to permit water flow through them while upper stories remain dry and livable. People would live in the same location having migrated upwards. Would these people be vertical climate change forced migrants, having migrated vertically to deal with climate change? Or is this simply sensible adaptation to one's ever-changing environment?

For a subset of forced migrants, the term "refugee" applies, although the two phrases are frequently used synonymously in common, rather than professional, parlance. In international law and humanitarian relief, a specific definition exists that "refugees" are people with:

[ ... ] a well-founded fear of being persecuted for reasons of race, religion, nationality, membership of a particular social group or political opinion is outside the country of his nationality and is unable or, owing to such fear, unwilling to avail himself of the protection of that country; or who, not having a nationality and being outside the country of his former habitual residence [ ... ] is unable or, owing to such fear, is unwilling to return to it. (UNHCR 1951/1967, p. 14)

This definition precludes vertical-forced migrants as being refugees in most circumstances (see Elden (2013) for a discussion of the vertical geopolitics of borders). As above, the same distance question applies for refugees, in that movement could be a matter of meters to cross an international border or it could be hundreds of kilometers without crossing into another country.

\subsection{Climate Change}

Two separate United Nations (UN) agencies are responsible for addressing different aspects of climate change and each has its own definition of the term. The Intergovernmental Panel on Climate Change (IPCC) was created by the UN's World Meteorological Organization (WMO) and UN Environment (UNEP). It publishes assessments of what member states can agree is the current state of climate change science. IPCC (IPCC 2013-2014, p. 1760) defines climate change as "a change in the state of the climate that can be identified (e.g., by using statistical tests) by changes in the mean and/or the variability of its properties, and that persists for an extended period, typically decades or longer". These words are clarified by defining "climate" as "the statistical description in terms of the mean and variability of relevant quantities over a period of time ranging from months to thousands or millions of years" (IPCC 2013-2014, p. 1760) followed by reference to the WMO typically taking thirty years as the timeframe over which climate is calculated.

UN Climate Change is the secretariat of the United Nations Framework Convention on Climate Change (UNFCCC) which deals with the intergovernmental policy and legal frameworks for addressing climate change topics. UNFCCC (1992, Article 1, para. 2) states that "'Climate change' means a change of climate which is attributed directly or indirectly to human activity that alters the composition of the global atmosphere and which is in addition to natural climate variability observed over comparable time periods". The IPCC's definition of "climate" is used. The difference in definitions of "climate change" is that the IPCC investigates any change in climate whereas UN Climate Change addresses only anthropogenic climate change. 
In aiming to determine causality from climate change or its impacts to population movements, a decision must be made regarding which definitions of "climate" and "climate change" to use. For developing a method to count and calculate climate change migrants, both definitions of "climate change" could be considered, with a separate tally for each. Given WMO's definition of "climate" as being calculated over thirty years, this choice would be reasonable for climate change migrants, but calculations could be made for different definitions of climate's time period in order to see how sensitive the results are to different definitions.

\subsection{Climate Change Causing Migration?}

Why climate change is purported to cause migration needs to be considered. Fundamentally, the suggestion is that climate change will make the environment much worse for living, thereby interfering with food, water, health, livelihoods, and infrastructure to the extent that people think they will be better off in other locations. At times, the alternatives might to move or to die. The presumption of all conditions inevitably becoming worse for everyone due to climate change has long been challenged in discussions of winners and losers (Glantz 1995).

For instance, many storms around the world are expected to become more intense and less frequent due to climate change (Walsh et al. 2016). A lower storm frequency means less experience in dealing with them while increased intensity requires more measures to reduce vulnerability. Without learning from experience and adjusting to increased intensity, both of which require investment, augmented storm damage could lead to migration-related decisions. The real cause of such migration would be the lack of investment rather than the storms changing due to climate change. Similarly, climate change influencing the environment involves factors both supporting and inhibiting the spread of insect-borne disease (Costello et al. 2009). In cases where insect-borne disease spread is supported by climate change, investment could avoid adverse effects, just as eradication campaigns continue today for diseases such as polio and dracunculiasis. If migration is induced by climate change influenced storms or diseases, then the migrants might be not be climate change migrants, but rather "lack of investment in dealing with climate change impacts" migrants.

Not all climate change impacts can necessarily be tackled with investment. As heat-humidity combinations over several days reach a regime precluding outdoor labor, and precluding indoor survival without expensive air-conditioning, people across large areas might have little option except to move or to die (Watts et al. 2018a, 2018b). Sea-level rise salinating freshwater supplies and agricultural land, while inundating previously dry land (depending on coastal morphological responses), has the potential for providing similar circumstances. Ocean acidification combined with warmer seas could possibly cause significant coral reef mortality, augmenting coastal erosion and wiping out coastal and shallow-water livelihoods. Projecting such outcomes in specific locations is difficult, but they remain realistic scenarios precipitating migration from climate change with little chance of averting the impacts.

\section{Counting and Calculating Climate Change Migrants}

With Section 2's understanding of the two key elements of climate change and migration, the next step in counting and calculating climate change migrants is to seek causality from climate change to population movement via climate change impacts. This approach requires a step-by-step understanding of how people would be labelled as climate change migrants.

\subsection{Attributing Migration to Climate Change Impacts}

The first step is counting individuals who are moving, leading to the challenges articulated in Section 2.1 regarding distance moved and determining labels, namely amongst "migrant", "forced migrant", and "refugee". If climate change refugee (or climate refugee) numbers are expected to have standing in international legal frameworks, then counting or calculating them is easy. At the moment, 
this number is zero and could be only zero, since the current legal definition of 'refugee' does not include moving for environmentally related reasons (Section 2.1).

If climate change migrants are being counted irrespective of refugee or other forced status-that is, people are moving any distance due to climate change-then Watts et al. (2018b, p. 594) suggest a baseline of "climate change is the sole contributing factor" to migration, hence no other factors influence the migration. This criterion is stringent, running into the challenge of being too confined compared to Baldwin (2014) description of why the discussion should be pluralized. It nonetheless serves to establish a minimum number of climate change migrants. Watts et al. (2018b) report this value as 4400 people, from the Carteret Islands, Papua New Guinea; several Alaskan villages; and possibly Isle de Jean Charles in Louisiana.

Watts et al. (2018b) aimed to achieve a baseline of climate change migrant numbers by considering only peer-reviewed literature, although there would be no guarantee that every peer-reviewed paper is entirely accurate. Furthermore, in the end, they referred to a USA government report (General Accounting Office 2003) with regards to Alaskan communities, because no peer-reviewed paper had independently published data as detailed and as comprehensive as General Accounting Office (2003). The scientific literature, in fact, has never been especially detailed or reliable in identifying and proving that specific communities or people are moving due to climate change impacts only or attributing parts of their movement to climate change impacts, making the task set by Watts et al. (2018b) extremely complex.

For instance, Ahmed (2018) starts with the assumption that climate change will force people to move within or from Bangladesh, without providing evidence of cause and effect. Specific examples given in Ahmed (2018) to demonstrate "climate refugees" are all weather-related disasters without demonstrating links to climate change by either definition. Other reasons for Bangladeshis migrating, post-disaster and irrespective of disasters, are given short shrift. The focus is on assumed climate change impacts with limited connection to the wider literature on Bangladeshi mobilities (e.g., Kumāra 2006; Mortuza 1992; Paul 2005).

Watts et al. (2018a) update the list of case studies from Watts et al. (2018b), explaining that subsequent work suggested that people from the Carteret Islands and Isle de Jean Charles are being forced to move for a variety of reasons, amongst which climate change impacts are included but are not the sole factor. From the beginning of understanding climate change impacts on low-lying atolls, Carteret Islanders were seen as perhaps being forced to move due to sea-level rise (Connell 1990), garnering significant attention for their plight (Rakova et al. 2009) despite the wider contexts in which Connell (1990) had placed his analysis. Those wider contexts were often subsumed by climate change migrant (and climate change refugee) rhetoric. A later study (Connell 2016) re-evaluated the contexts, suggesting that the Carteret situation is caused more by local human changes such as constructing a sea wall as well as natural variations, even while other authors continue to label the situation as "climate-related migration" partly because sea walls did not help (Schwerdtle et al. 2018).

The construction of sea walls is of particular interest in trying to attribute forced movement to climate change. Vunidogoloa, Narikoso, and Denimanu are Fijian villages which are mentioned in studies as moving inland because climate change impacts have led to the sea encroaching (McNamara and Combes 2016). Hermann and Kempf (2017) deconstruct such discussions, supporting the notion that little physical evidence exists for climate change impacts causing the villages to move. This point is especially important given that poorly designed sea walls can cause or exacerbate beach and other coastal erosion (Pilkey and Wright 1988; Thomas and Hall 1992). Even if climate change impacts were one factor amongst many for these Fijian villages, it is unclear how much of a role climate change impacts are proven to have played in the decision to move, because the evidence to make this judgement has not been collected.

Consequently, from the list of climate change migrants in Watts et al. (2018b), only the Alaskans from General Accounting Office (2003) (validated more recently by Albert et al. (2018) and Manrique et al. (2018)) remain considered as forced migrants with climate change as the only factor causing their 
move (Watts et al. 2018a). All these villages seem likely to move several kilometers inland, so still within Alaska and near their communities of origin, yet nonetheless forced by climate change impacts.

Outside of these Alaskan villages, people have a multitude of reasons for moving, even when impacted substantially by climate change, making attribution difficult. Therefore, the next step in counting and calculating climate change migrants would be establishing how much climate change influences their decisions to move. Research methods such as interviews, surveys, focus groups, and participatory activities can gather data in this regard and have been applied for the topic (Findley 1982; van der Velde et al. 2009; Vargas-Silva 2012). Limitations and ethical dilemmas of these methods are well-known in that people might not always provide their complete views, deliberately or inadvertently, while viewpoints expressed are always subject to power relations and interpretation (Cooke and Kothari 2001; Hickey and Mohan 2004; Lykes et al. 2011).

Overall, for almost all cases, attributing movement to climate change wholly or partially is not straightforward. Robust, repeatable, and verifiable methodologies might not exist apart from the (currently few) clear-cut instances such as Alaska. This situation might change in the future.

\subsection{Time Scale of the Movement}

Following attribution, the second step in counting and calculating climate change migrants is to establish the time scale of the population movements. If it were a requirement that people move permanently, then counting would need to wait until the migrants had died, as it could not be certain that they would never return otherwise. There is no specific need to establish permanence or expectations of permanence. Migration has always been an important and often essential part of human life and livelihoods (Fiddian-Qasmiyeh et al. 2016; Meir 1986; Stojanov 2014; Urry 2007). Such population movement studies have long established that people are not necessarily sedentary; can presume to move permanently but then return; or might be circular migrants meaning that they move temporarily and return temporarily to their place of origin in a continuing cycle which might be seasonal or for several years at a time in each location (see also Bellwood 2013; Solé et al. 2016).

The temporal key for counting and calculating climate change migrants, perhaps, is to be time-independent regarding movement while seeking climate change impacts over the timeframe of climate which is at least thirty years. If people move, then they are included in the tally, no matter how long it takes them to move and no matter how long they remain in their new location. In such cases, an inconsistency might emerge if people purport to move due to climate change impacts, deciding later to move back to their original location irrespective of continuing or perceived climate change impacts. People might also claim to move due to climate change impacts when they are really seeking other opportunities. They might determine that they do not like their destination, so they move back to their origin or move to another location, no longer mentioning climate change-or perhaps claiming climate change impacts as the reason for moving from their new place.

Counting, calculating, and projecting climate change migrant numbers through time produce another conundrum. Projections regarding climate change and its impacts have been studied for the next 10,000 years (Clark et al. 2016). Projecting human responses to climate change impacts over a similar timeframe, or a fraction thereof, is fraught with difficulty given how rapidly society and technology change.

While speculation, scenarios, and futurology are important components within this science (Attali 2011; Goldthorpe 1971), little confidence would exist regarding accurate and precise indications of how people might or might not respond to environmental stimuli over centuries and millennia, especially in terms of population movements. At these time scales, fiction might provide as much help as peer-reviewed studies. Aside from forced migration novels such as John Steinbeck's The Grapes of Wrath (1939), notable futurist novels involving forced migration include Arthur C. Clarke's The Songs of Distant Earth (1986), Margaret Atwood's The MaddAddam Trilogy (2003, 2009, 2013), and Cormac McCarthy's The Road (2006). Examples of science fiction movies about environmental migration are Waterworld (1995) and The Day After Tomorrow (2004). At the extreme end of environmental or climate 
change, migrants would be fleeing the Earth (so perhaps they are refugees?) which is slowly dying due to human activity, such Ben Elton's novel Stark (1989) and the movie WALL-E (2008). Making defensible projections of such scenarios, the decision-making processes, and the success or failure would not be feasible, apart from the range being from zero to the entire human population.

\subsection{Space Scale of the Movement}

The third step in counting climate change migrants is to establish the spatial scale of the population movements. Section 2.1 explained that no set answer exists regarding how far people must move in order to be considered a migrant or a refugee. For the purposes of counting and calculating, it might be a useful step to adopt part of the legal definition of "refugee" that the migrants must cross an international border-or, at minimum, a political jurisdiction which could include municipal boundaries. Even though such boundaries are comparatively clearly delineated, notwithstanding border disputes and arbitrariness, would this scoping actually assist?

One consequence would be an inevitable underestimate of numbers, because internal movements would not be included. Regarding internal movements, the Alaskans identified in General Accounting Office (2003) are moving due to climate change impacts only, so they should be counted as climate change migrants. Except, by moving their villages, they are moving their municipal jurisdiction, so technically they are not crossing a municipal boundary. Alaska has boroughs, rather than counties, and it seems unlikely that all villages will traverse a borough boundary, again potentially removing them from the count. As another example, if tens of thousands of people had to move from Shanghai or southern Bangladesh due to climate change impacts, then depending on exactly where they moved would determine whether or not a political boundary had been crossed. It is certainly unlikely that all would move across an international border, since they could move hundreds of kilometers and still be in the same country.

Furthermore, regarding international borders, it is possible to migrate across an ocean without crossing an international border. France has five departments and regions which are fully part of the country and the European Union, but which are not in Europe: French Guiana (South America), Guadeloupe (Caribbean), Martinique (Caribbean), Mayotte (Indian Ocean), and La Réunion (Indian Ocean). Montserrat is a UK Overseas Territory in the Caribbean and, after its volcano started erupting in 1995, more than two-thirds of this Caribbean island's population ended up leaving, many to the UK. Although Montserrat is not fully within the UK, there is not an international border between the island and the UK, so it would unclear whether or not Montserratians could be "volcano refugees" in principle even though they are "volcano migrants" in practice. Conversely, there are no direct commercial Montserrat-UK travel options, so most people would travel via the country of Antigua and Barbuda - and perhaps additionally other countries such as the USA - meaning that they have crossed an international border. Similarly, if climate change impacts undermine infrastructure or livelihoods in northern Norwegian towns such as Vardø or Nesseby, so people decide to move south to Trondheim or Oslo, packing up and driving their possessions would find the quickest route through Finland and Sweden-moving internally but crossing international borders.

Political jurisdictions and their boundaries change, including international borders, adding further complications to categorizing spatial movement. Bangladesh is often cited as being a country at high risk of producing "climate refugees" (Ahmed 2018). The country gained independence from Pakistan in 1971, which followed the 1948 partition creating India and Pakistan as separate, sovereign states. Had these country-level splits not occurred, then most Bangladeshi migrants, climate change related or not, would probably be moving internally as they often did, (i) overland to other parts of India prior to 1948 when Bangladesh was East Bengal, and then (ii) when it was East Pakistan until 1971, moving to West Pakistan. In 2019 and beyond, Bangladeshis are still moving for ostensibly similar reasons as before, including political persecution, sometimes moving within Bangladesh and sometimes crossing into Assam, India or other countries, although recently not going to Pakistan much (e.g., Kumāra 2006; Swain 1996; UNICEF 2018). 
Such arbitrariness of some international borders, and when they were created, leads to an arbitrary change from forced or unforced migrants to potential refugees for some people moving. The same argument could be made for South Sudan gaining independence in 2011 and Timor-Leste becoming sovereign in 2002. Independence movements continue in Greenland, New Caledonia, Nevis, Québec, and Scotland. Over the decades-scale impacts of climate change potentially forcing movement, international borders are likely to appear and disappear. Yemen and Germany each unified their two parts in 1990. Land swaps to realign borders occur as with Netherlands and Belgium in 2016 along the River Meuse/Maas. Sub-national borders are not immune from changes. In Toronto, Canada, a new municipal jurisdiction with its own government was created in 1954 and then provincially dictated amalgamation dissolved several of its constituent parts in 1998.

Moreover, even if migration is forced by climate change impacts, the need to cross a jurisdictional border might result from non-climate change related factors. Many coastal countries have reasonably high topography such as Mauritius and Barbados. In many locations in these countries, a relatively short move from coastal locations, without crossing a political jurisdiction, should leave people high enough above sea level to avoid the worst expected impacts from sea-level rise until at least the year 2100. Such a move might not be feasible because so much land is already owned or otherwise allocated. Uses include natural heritage protection, ancestral land, cemeteries, resorts, golf courses, and agriculture. Meanwhile, moving inland in countries such as Comoros and St. Lucia might lead to living in volcano or landslide hazard zones. Consequently, people might leave their country because they are not permitted to move internally or because it increases their risks to environmental hazards. In these circumstances, are climate change impacts the real or predominant cause of moving? Would other factors supersede climate change, namely, current land use practices or lack of resources allocated for supporting safe internal migration?

Thus, even a fairly straightforward and monitorable decision such as crossing into another jurisdiction does not lead to unambiguous counting or calculating of climate change migrants, yielding large error bars. Yet an underestimate is not necessarily a detrimental situation, because it establishes a minimum level, similarly to the calculations in Watts et al. (2018b). If a good percentage of a parish's or country's population move internally, then the underestimate (often close to zero) might be so low as to be unusable for policy and action (see also the discussion on "maximalists" and "minimalists" in Klepp 2017).

\subsection{Summary}

Given the discussion in this section, a robust, repeatable, and verifiable method for counting and calculating climate change migrants might not be feasible without arbitrary, inconsistent, and unreliable choices to begin, the baselines for which might change. The complexities raised regarding attribution, time scale, and space scale corroborate and add to the concerns about the already articulated complexities of climate change migration (Baldwin 2013; Brzoska and Fröhlich 2016; Nicholson 2014). It would certainly be possible to establish a minimum number or a set of minimum numbers using different assumptions, but they would have large error bars and these numbers might not be useful for policy and action.

\section{Subjectivity of Decisions for Calculating Climate Change Migrants and Non-Migrants}

Section 3 demonstrated that, ultimately, counting and calculating numbers of climate change migrants depend on the definitions selected. One decision described is how much climate change needs to influence migration in order for the migrants to be included in the count. Then, decisions are needed regarding the time and space scales of movement. The descriptions show how these decisions are principally subjective, meaning that they would be easily disputable leading to different results depending on who is counting, and perhaps, the political reasons for making the count. As with the arbitrary decision of defining climate change and its timeframe (Section 2.2), multiple calculations could be completed to determine high and low values. The range would be large, leading to the vastly 
varying numbers which are reported (Gemenne 2011), usually with limited empirical or verifiable basis (Brzoska and Fröhlich 2016; Hartmann 2010; Nicholson 2014). That is, labelling or not labelling people as "climate change migrants" or variations, and hence the total numbers tabulated, becomes to a large extent a political choice.

The choice of vocabulary is also political. With respect to migrants, "climate" is often conflated with "climate change" despite science clearly differentiating these terms (Section 2.2). Phrases such as "climate migrants" and "climate refugees" are used to refer to people moving due to climate change, confusing the causation amongst (i) weather (which, over decades, is "climate"), (ii) changes in weather statistics over decades (IPCC's definition of "climate change"), and (iii) changes in weather statistics over decades due to human activities (UN Climate Change's definition of "climate change"). Further conflation is made with all "environmental migrants" and "environmental refugees", even though climate change is one influence on the environment amongst many. Environmental migration has long occurred for a range of reasons from dam construction (World Commission on Dams 2000) to volcanic eruptions (Lane et al. 2003).

Another political element in vocabulary is the choice of "refugees", "migrants", "forced migrants", "population movement", and variations. Objections to using the term "refugee" for climate change movement are (i) the lack of inclusion of environmental reasons within UNHCR 1951/1967 (UNHCR 1951/1967) and (ii) fear that including environment-related reasons in the "refugee" definition will force the entire document to be renegotiated and potentially weakened (Hall 2013; IOM 2014; Nishimura 2015). Others, including some of the people directly affected, consider the labelling of people as "climate (change) refugees" to be pejorative. As McNamara and Gibson (2009) report, many Pacific islanders potentially affected by forced migration due to climate change do not wish to be termed "refugees" and do not wish to be seen as poor, helpless victims. Wyett (2014) describes the policy from Kiribati at the time of "migration with dignity", aiming for population movement related to climate change to be conducted as the last option and on the terms of the people who are moving, not as forced migration with the migrants needing external assistance.

These considerations tend not to be fully incorporated into the numerous proposals for mechanisms to formalize climate change related migrants such as "The peninsula principles on climate displacement within states" (Leckie 2014) and a new convention (Docherty and Giannini 2009). Many other practical problems emerging from counting and calculating climate change migrants, as discussed here, are also not fully addressed in these attempts to define, label, or otherwise produce a specific, delineated category.

Family-level dynamics are one example. If one family member-perhaps the one bringing in the most income-decides to migrate due to experienced, perceived, or presumed climate change impacts, and this individual brings the rest of the family, are all family members equivalently climate change migrants? Rather than counting people, the problem could be reformulated as counting families or households. This task would entail delving into the extensive literature on how to define a family or a household (e.g., Malinowksi 1913; Solien 1960) and interpreting such discussions in the context of assumptions about cultures and cultural superiority. An alternative would be to total the number of communities or settlements which are relocating, again under a presumption that these units are easily delineated and are meaningful, which is not necessarily the case (see Titz et al. 2018).

A further difficulty in counting climate change migrants regardless of the unit of analysis is that people will sometimes move based on perceived or expected climate change impacts without having witnessed many or any impacts. Connell (2016) explains this possibility for the Carteret Islands, indicating the potential that the desire to move has impetus in assumptions or discourses of climate change migration rather than in definitely experienced impacts of climate change causing migration. In Miami-Dade County, Florida, Keenan et al. (2018) indicate that prices of single-family dwellings are increasing faster at higher elevations than at lower elevations, seemingly because of increased flooding at lower elevations. They are careful in how they express their findings, especially in terms of caution about linking climate change with changes in flooding or perceived changes in flooding. They 
explain how perceptions of future climate change impacts are likely to influence the observed property value trends. The question remains that if people move due to assumed or speculative climate change impacts, should they be considered to be climate change migrants, whether or not their expectations of climate change impacts are eventually met by reality?

Climate change impacts might remove migration options for people who would otherwise wish to move or who might consider moving. That is, given that climate change impacts are forcing some people to move, namely in Alaska, what are the prospects for climate change impacts forcing non-migration? An example could be a couple in northern England saving up to retire in southern Spain when climate change is attributed to the increasing frequency, length, and intensity of heat waves (Achebak et al. 2018) making it dangerous to be outdoors and, in the end, dangerous to be indoors without air conditioning. Consequently, the couple does not move, remaining in their northern England home. Attribution science is reaching the point where specific weather parameters can sometimes be connected to climate change with a high degree of confidence (National Academies of Sciences, Engineering, and Medicine 2016). It is trickier to determine whether or not this couple are climate change forced non-migrants. They could stay indoors in Spain with air conditioning during the heat waves, provided they could afford the electricity bill and wish to consume this amount of electricity. They could retire to coastal Germany or southern England instead, again provided they would wish to and could afford it.

Another example would be a landholder with a small coastal plot who has been saving up to move when sea-level rise starts salinating and inundating their land. As they have not been able to afford insurance or companies would not sell them insurance, the landholder's savings are now used trying to survive each year to the point that they can no longer afford to move. They become trapped on their coastal land due to climate change impacts-or possibly due to lack of external assistance to support them with insurance or moving. This scenario parallels experiences in the Czech Republic in which people wish to move from their regularly flooding house, but they cannot afford to move because their property is unsellable and uninsurable (Stojanov et al. 2015). This Czech example could be used to forecast by analogy (Glantz 1988) for climate change forced non-migration, because the Czech floods have not been attributed to climate change.

The same difficulties and complexities for calculating climate change migrants (Sections 2 and 3) appear for calculating climate change non-migrants: definitions, attribution, spatial scales, and temporal scales. If all these problems could be overcome, then for counting and calculating, should climate change non-migrants be subtracted from climate change migrants to yield a net climate change migration total? The result might be negative numbers of climate change migrants.

Given that counting and calculating numbers of climate change migrants and non-migrants involve political choices to reach the tallies, meaning that the results are inherently political, is it worthwhile making the effort? If numbers, or even their ranges, might be robust, advantages might exist. Certainly, the Alaskan villages are examples of people being forced to move only because of climate change. In these instances, staying would require such extensive engineering and maintenance of the coastlines that moving might be cheaper and easier (plus, the communities would be changed about as much by in-situ actions as they will be changed by moving). Coastal engineering might not even work for very long. The Alaskan numbers are robust and verifiable, providing an absolute minimum to the numbers of climate change migrants for the moment.

As climate change impacts become more evident over coming decades, shorelines will continue to be monitored to determine their responses to sea-level rise (especially from thermal expansion and perhaps from ice sheet collapse, if it starts); ocean acidification; changing ecosystems, especially coral reefs; altered storm, wave, and current regimes; and freshwater supplies. For now, the geomorphological, ecological, and biogeochemical responses of tidal and coastal zones to climate change impacts are packed with uncertainties, unknowns, and complexities. The range of coastal outcomes under similar environmental changes runs from substantial retreat and disappearing islands through to expansion in area and volume (Albert et al. 2016; Ford 2012; Yates et al. 2013). 
Consequently, going beyond the numbers from the clear-cut case studies in Alaska might be unworkable, so explanatory and predictive models of climate change migrants and non-migrants would cover wide spectra with substantive error bars. This situation does not preclude pursuing the work for the sake of science, to establish likely maxima, minima, distributions, and probability functions. In doing so, one outcome to be aware of and to try to avoid is that pre-established ideological perspectives will tend to use selected results to justify existing viewpoints rather than developing viewpoints which encompass all the results (Nicholson 2014). Specifically, political interests intent on disparaging climate change impacts as a problem would adopt the low estimates whilst those seeking to amplify concerns about climate change impacts would adopt the high estimates.

This statement is not hypothetical. Watts et al. (2018b), using numerous nuances and provisos, reported counts of people migrating due to climate change impacts. They concluded that approximately 4400 people fell into this category at the time of the report, but by 2100 , in the absence of concerted action, the number could reach one billion plus or minus fifty percent. Reporting Watts et al. (2018b), the center-left UK-based newspaper The Independent, known for its pro-environmentalist stances, published the headline "Climate change could force more than a billion people to flee their homes, says major health report" for a 31 October 2017 story highlighting the potential negative health effects of climate change. One week later, the USA-based center-right Inside Sources published the headline "Lancet Study Finds Climate Change Has Uncertain Impact on Migration" emphasizing the 4400 number in a fairly balanced piece which highlighted the uncertainties. Comments on "climate change refugees" have also been used to fuel unscientific anti-immigrant rhetoric, such as the UK right-wing tabloid Daily Mail reporting on IPCC (IPCC 2013-2014) imbalanced human security chapter with the headline "UK warned of 'climate change flood of refugees': Droughts and heatwaves could force millions to flee their country" (1 April 2014).

Examining climate change migrants including through (but not limited to) quantification could be tackled by careful, rigorous, systematic science, especially to analyze what could and could not be achieved. Research methods can explore whether or not it would be appropriate, useful, and usable to try to assign a number or label to a process as complex as migration and non-migration with different degrees of being forced and voluntary, given all the factors involved. Mixed motives for migration and non-migration-within individuals, families, households, and populations-could be explored, developing models to determine percentages of different reasons inputting into a decision. Methodologies would draw on previous studies, such as for Canada (Currie and Halli 1989) and the Philippines (Amacher et al. 1989).

Science can be a powerful process to identify, deconstruct, and overcome these complexities, as long as the limitations, provisos, biases, nuances, and subtleties are always admitted and accepted. Instead, political agendas exist on this topic from many standpoints, pushing forward non-scientific drivers for counting and calculating in order to support existing beliefs (Baldwin et al. 2014; Bettini 2013; Hartmann 2010). In the USA, a militarized and securitized response has dominated (Hartmann 2010). Elsewhere, dystopian narratives prevail. Humanitarian needs (based on climate change migrants being victims) and securitization (based on climate change migrants being threats) are pushed to the forefront (Bettini 2013), thereby circumventing scientific discussions of definitions, categories, labels, and complexities. Nicholson (2014) even challenges the point of trying to determine causality which he explains might not be feasible while, for Syria, Fröhlich (2016) deconstructs the superficially presumed causality from climate change to migration to conflict.

Ultimately, these analyses combined with the discussion in Section 3 lead to an understanding regarding root causes of forced migration or forced non-migration which might be linked to climate change: It is typically a lack of support mechanisms to deal with climate change impacts, rather than the climate change or its impacts per se, which forms the root causes. Such migration and non-migration are, in effect, simultaneously (i) a failure to adapt to climate change due to lack of support, thereby forcing (ii) non-migration as adaptation or migration as adaptation to climate change impacts. These points are imbued with and driven by deeply entrenched political processes constructing climate 
change as a physical manifestation without connecting to the underlying politics of why the physical changes are happening (see analyses in Felli and Castree 2012; Klepp and Chavez-Rodrìguez 2018; Klepp and Herbeck 2016; Hartmann 2010; Nicholson 2014; Stojanov 2014).

The Alaskan villages represent an exception to this analysis and more exceptions could yet emerge. For the most part, discussion about counting and calculating climate change migrants tends to make numerous assumptions about definitions, attributions, and linear cause-and-effect pathways. These assumptions do not stand up to scrutiny and do not admit or try to tackle the inherent complexities.

\section{Conclusions}

Trying to label, count, and calculate people as climate change migrants-or as variations such as climate refugees, climate change refugees, and environmental refugees-poses an interesting and challenging scientific problem. With clear definitions and explicit starting assumptions, some headway can be made in tabulating the numbers, but mainly as minimal values with large error bars. Changing baselines, legitimate concerns about the assumptions, and complexities question the usefulness of even these calculations for policy and action.

This situation contrasts with efforts to quantify in order to justify pre-decided policies and actions. Underestimates could justify an already decided political stance that action on climate change need not be substantive. Overestimates could justify a political stance about preventing migration because migration is presumed to be inherently bad or a political stance that climate change is a massive, possibly existential, threat to humanity. It is straightforward to ensure that numbers present what a political stance wishes them to say, in the face of the methodological decisions which must be made yet which are inherently subjective and arbitrary.

Given these methodological challenges and the political uses of the resulting numbers, a robust, repeatable, and verifiable methodology might not be feasible for counting and calculating climate change migrants. Instead, even while the politics drives the calculation methodologies and the numbers, the numbers are then used to pose as an objective and indisputable reason to implement policies which were desired anyway, trying to bypass the political or ideological reasons for those policies. This includes attaching labels to people based on decisions which are made about attributing movement to climate change, the spatial scales of movement, and the temporal scales of movement.

Ultimately, counting, calculating, and labelling climate change migrants and non-migrants depend on the definitions selected and debatable choices. The futility of finding a robust, repeatable, and verifiable methodology could also mean that the attempts to do so distract from those who are moving only due to climate change, such as in Alaska. Apart from those few exceptions, which might expand in the future, labelling or not labelling people as "climate change migrants" or variations is a subjective, and hence political, choice. Efforts would be better spent contributing to the ongoing efforts to understand people's motivations for migrating or not migrating under all circumstances. In such work, climate change would be one potential factor amongst many, rather than starting with the assumed inevitability of climate change causing migration.

Funding: The Lancet Countdown's work is supported by an unrestricted grant from the Wellcome Trust (200890/Z/16/Z).

Acknowledgments: This paper was completed as part of the Lancet Countdown project (Tracking the connections between public health and climate change) http://www.lancetcountdown.org.

Conflicts of Interest: The author declares no conflicts of interest.

\section{References}

Abubakar, Ibrahim, Robert W. Aldridge, Delan Devakumar, Miriam Orcutt, Rachel Burns, Mauricio L. Barreto, Poonam Dhavan, Fouad M. Fouad, Nora Groce, Yan Guo, and et al. 2018. The UCL-Lancet Commission on Migration and Health: The health of a world on the move. The Lancet 392: 2606-54. [CrossRef]

Achebak, Hicham, Daniel Devolder, and Joan Ballester. 2018. Heat-related mortality trends under recent climate warming in Spain: A 36-year observational study. PLoS Medicine 15: e1002617. [CrossRef] [PubMed] 
Ahmed, Bayes. 2018. Who takes responsibility for the climate refugees? International Journal of Climate Change Strategies and Management 10: 5-26. [CrossRef]

Albert, Simon, Javier X. Leon, Alistair R. Grinham, John A. Church, Badin R. Gibbes, and Colin D. Woodroffe. 2016. Interactions between sea-level rise and wave exposure on reef island dynamics in the Solomon Islands. Environmental Research Letters 11: 054011. [CrossRef]

Albert, Simon, Robin Bronen, Nixon Tooler, Javier Leon, Douglas Yee, Jillian Ash, David Boseto, and Alistair Grinham. 2018. Heading for the hills: Climate-driven community relocations in the Solomon Islands and Alaska provide insight for a $1.5^{\circ} \mathrm{C}$ future. Regional Environmental Change 18: 2261-72. [CrossRef]

Amacher, Gregory S., Wilfrido Cruz, Donald Grebner, and William F. Hyde. 1989. Environmental Motivations for Migration: Population Pressure, Poverty, and Deforestation in the Philippines. Land Economics 74: 92-101. [CrossRef]

Attali, Jacques. 2011. A Brief History of the Future: A Brave and Controversial Look at the Twenty-First Century. New York: Arcade.

Baldwin, Andrew. 2013. Racialisation and the Figure of the Climate-Change Migrant. Environment and Planning A: Economy and Space 45: 1474-90. [CrossRef]

Baldwin, Andrew. 2014. Pluralising Climate Change and Migration: An Argument in Favour of Open Futures. Geography Compass 8: 516-28. [CrossRef]

Baldwin, Andrew, Chris Methmann, and Delf Rothe. 2014. Securitizing 'Climate Refugees': The Futurology of Climate-induced Migration. Critical Studies on Security 2: 121-30. [CrossRef]

Bellwood, Peter. 2013. First Migrants: Ancient Migration in Global Perspective. Chichester: Wiley Blackwell.

Bettini, Giovani. 2013. Climate Barbarians at the Gate? A Critique of Apocalyptic Narratives on 'Climate Refugees'. Geoforum 45: 63-72. [CrossRef]

Brzoska, Michael, and Christiane Fröhlich. 2016. Climate Change, Migration and Violent Conflict: Vulnerabilities, Pathways and Adaptation Strategies. Migration and Development 5: 190-210. [CrossRef]

Clark, Peter U., Jeremy D. Shakun, Shaun A. Marcott, Alan C. Mix, Michael Eby, Scott Kulp, Anders Levermann, Glenn A. Milne, Patrik L. Pfister, Benjamin D. Santer, and et al. 2016. Consequences of twenty-first-century policy for multi-millennial climate and sea-level change. Nature Climate Change 6: 360-69. [CrossRef]

Connell, John. 1990. The Carteret Islands: Precedents of the Greenhouse effect. Geography 75: 152-54.

Connell, John. 2016. Last days in the Carteret Islands? Climate change, livelihoods and migration on coral atolls. Asia Pacific Viewpoint 5: 3-15. [CrossRef]

Cooke, Bill, and Uma Kothari, eds. 2001. Participation: The New Tyranny. London: Zed Books.

Costello, Anthony, Mustafa Abbas, Adriana Allen, Sarah Ball, Sarah Bell, Richard Bellamy, Sharon Friel, Nora Groce, Anne Johnson, Maria Kett, and et al. 2009. Managing the health effects of climate change. The Lancet 373: 1693-733. [CrossRef]

Currie, Raymond F., and Shiva S. Halli. 1989. Mixed motivations for migration in the urban prairies: A comparative approach. Social Indicators Research 21: 481-99. [CrossRef]

Docherty, Bonnie, and Tyler Giannini. 2009. Confronting a rising tide: A proposal for a convention on climate change refugees. Harvard Environmental Law Review 33: 349-403. [CrossRef]

Elden, Stuart. 2013. Secure the volume: Vertical geopolitics and the depth of power. Political Geography 34: 35-51. [CrossRef]

Felli, Romain, and Noel Castree. 2012. Neoliberalising Adaptation to Environmental Change: Foresight or Foreclosure? Environment and Planning A 44: 1-4. [CrossRef]

Fiddian-Qasmiyeh, Elena, Gil Loescher, Katy Long, and Nando Sigona, eds. 2016. The Oxford Handbook of Refugee and Forced Migration Studies. Oxford: Oxford University Press. [CrossRef]

Findley, Sally E. 1982. Migration Survey Methodologies: A Review of Design Issues. Liège: International Union for the Scientific Study of Population.

Ford, Murray. 2012. Shoreline changes on an urban atoll in the Central Pacific Ocean: Majuro Atoll, Marshall Islands. Journal of Coastal Research 28: 11-22. [CrossRef]

Foresight. 2011. Migration and Global Environmental Change: Final Project Report; London: The Government Office for Science.

Fröhlich, Christiane. 2016. Climate Migrants as Protestors? Dispelling Misconceptions about Global Environmental Change in Pre-Revolutionary Syria. Contemporary Levant 1: 38-50. [CrossRef]

Fröhlich, Christiane. 2017. A Critical View on Human Mobility in Times of Crisis. Global Policy 8: 5-11. [CrossRef] 
Gemenne, François. 2011. Why the numbers don't add up: A review of estimates and predictions of people displaced by environmental changes. Global Environmental Change 21: S41-S49. [CrossRef]

General Accounting Office. 2003. Alaska Native Villages: Most Are Affected by Flooding and Erosion But Few Qualify for Federal Assistance; Washington: United States General Accounting Office.

Glantz, Michael H., ed. 1988. Societal Responses to Regional Climatic Change: Forecasting by Analogy. Boulder: Westview.

Glantz, Michael H. 1995. Assessing the impacts of climate: The issue of winners and losers in a global climate change. Studies in Environmental Science 65: 41-54.

Goldthorpe, John H. 1971. Theories of Industrial Society: Reflections on the recrudescence of historicism and the future of futurology. European Journal of Sociology/Archives Européennes de Sociologie 12: 263-88. [CrossRef]

Hall, Nina. 2013. Moving Beyond its Mandate? UNHCR and Climate Change Displacement. Journal of International Organisations Studies 7: 91-108.

Hartmann, Betsy. 2010. Rethinking Climate Refugees and Climate Conflict: Rhetoric, Reality and the Politics of Policy Discourse. Journal of International Development 22: 233-46. [CrossRef]

Hermann, Elfriede, and Wolfgang Kempf. 2017. Climate Change and the Imagining of Migration: Emerging Discourses on Kiribati's Land Purchase in Fiji. The Contemporary Pacific 29: 231-63. [CrossRef]

Hickey, Samuel, and Giles Mohan, eds. 2004. Participation-From Tyranny to Transformation? Exploring New Approaches to Participation in Development. London: Zed Books.

IOM. 2014. IOM Outlook on Migration, Environment and Climate Change. Geneva: IOM (International Organization for Migration).

IPCC. 2013-2014. Fifth Assessment Report, Working Group II Glossary. Geneva: IPCC (Intergovernmental Panel on Climate Change).

Keenan, Jesse M., Thomas Hill, and Anurag Gumber. 2018. Climate gentrification: From theory to empiricism in Miami-Dade County, Florida. Environmental Research Letters 13: 054001. [CrossRef]

Klepp, Silja. 2017. Climate Change and Migration. In Oxford Research Encyclopedia of Climate Science. Oxford: Oxford University Press. [CrossRef]

Klepp, Sijla, and Libertad Chavez-Rodrìguez, eds. 2018. A Critical Approach to Climate Change Adaptation. Discourses, Policies and Practices. Abingdon: Routledge.

Klepp, Silja, and Johannes Herbeck. 2016. The politics of environmental migration and climate justice in the Pacific region. Journal of Human Rights and the Environment 7: 54-73. [CrossRef]

Kumāra, Braja Bihārī, ed. 2006. Illegal Migration from Bangladesh. New Delhi: Concept Publishing.

Lane, Lucille R., Graham A. Tobin, and Linda M. Whiteford. 2003. Volcanic Hazard or Economic Destitution: Hard Choices in Baños, Ecuador. Environmental Hazards 5: 23-24. [CrossRef]

Leckie, Scott, ed. 2014. Land Solutions for Climate Displacement. Abingdon: Routledge.

Lykes, M. Brinton, Rachel M. Hershberg, and Kalina M. Brabeck. 2011. Methodological Challenges in Participatory Action Research with Undocumented Central American Migrants. Journal for Social Action in Counseling and Psychology 3: 22-35.

Malinowksi, Bronisław. 1913. The Family among the Australian Aborigines. London: University of London Press.

Manrique, David Romero, Serafín Corral, and Ângela Guimarães Pereira. 2018. Climate-related displacements of coastal communities in the Arctic: Engaging traditional knowledge in adaptation strategies and policies. Environmental Science and Policy 85: 90-100. [CrossRef]

Martin, Brian. 1979. The Bias of Science. Canberra: Society for Social Responsibility in Science.

McNamara, Karen E., and Helene Jacot Des Combes. 2016. Planning for Community Relocations Due to Climate Change in Fiji. International Journal of Disaster Risk Science 6: 315-19. [CrossRef]

McNamara, Karen E., and Chris Gibson. 2009. We do not want to leave our land': Pacific ambassadors at the United Nations resist the category of 'climate refugees. Geoforum 40: 475-83. [CrossRef]

Meir, Avinoam. 1986. Demographic Transition Theory: A Neglected Aspect of the Nomadism-Sedentarism Continuum. Transactions of the Institute of British Geographers 11: 199-211. [CrossRef]

Mortuza, Syed Ali. 1992. Rural-Urban Migration in Bangladesh: Causes and Effects. Dhaka: D. Reimer.

National Academies of Sciences, Engineering, and Medicine. 2016. Attribution of Extreme Weather Events in the Context of Climate Change. Washington: National Academies Press. [CrossRef]

Nicholson, Calum. 2014. Climate Change and the Politics of Causal Reasoning: The Case of Climate Change and Migration. The Geographical Journal 180: 151-60. [CrossRef] 
Nishimura, Lauren. 2015. 'Climate Change Migrants': Impediments to a Protection Framework and the Need to Incorporate Migration into Climate Change Adaptation Strategies. International Journal of Refugee Law 27: 107-34. [CrossRef]

Paul, Bimal Kanti. 2005. Evidence against disaster-induced migration: The 2004 tornado in north-central Bangladesh. Disasters 29: 370-85. [CrossRef]

Pilkey, Orrin H., and Howard L. Wright III. 1988. Seawalls versus beaches. Journal of Coastal Research SI 4: 41-64. [CrossRef]

Rakova, Ursula, Luis Patron, and Citt Williams. 2009. How-to Guide for Environmental Refugees. United Nations University Our World, June 16. Available online: https://ourworld.unu.edu/en/how-to-guide-forenvironmental-refugees (accessed on 28 September 2018).

Ritchey, P. Neal. 1976. Explanations of Migration. Annual Review of Sociology 2: 363-404. [CrossRef]

Schwerdtle, Patricia, Kathryn Bowen, and Celia McMichael. 2018. The health impacts of climate-related migration. BMC Medicine 16: 1. [CrossRef]

Solé, Carlota, Sonia Parella, Teresa Sordé Martí, and Sonja Nita. 2016. Impact of Circular Migration on Human, Political and Civil Rights: A Global Perspective. Basel: Springer. [CrossRef]

Solien, Nancie L. 1960. Household and Family in the Caribbean: Some Definitions and Concepts. Social and Economic Studies 9: 101-6.

Stojanov, Robert, ed. 2014. Migration as Adaptation? Population Dynamics in the Age of Climate Variability. Brno: Global Change Research Centre, Academy of the Sciences of the Czech Republic.

Stojanov, Robert, Ilan Kelman, and Barbora Duží. 2015. Floods and migration in the Czech Republic. Forced Migration Review 49: 49-50.

Swain, Ashok. 1996. Displacing the Conflict: Environmental Destruction in Bangladesh and Ethnic Conflict in India. Journal of Peace Research 33: 189-204. [CrossRef]

Thomas, R. S., and B. Hall. 1992. Seawall Design. Oxford: Butterworth-Heinemann. [CrossRef]

Titz, Alexandra, Terry Cannon, and Fred Krüger. 2018. Uncovering 'Community': Challenging an Elusive Concept in Development and Disaster Related Work. Societies 8: 71. [CrossRef]

UN Commission on Human Rights. 1998. Measures to Improve the Situation and Ensure the Human Rights and Dignity of All Migrant Workers. Report of the Working Group of Intergovernmental Experts on the Human Rights of Migrants Submitted in Accordance with Commission on Human Rights Resolution, 1997/15. E/CN.4/1998/76. New York: United Nations Economic and Social Council.

UNFCCC (United Nations Framework Convention on Climate Change). 1992. United Nations Framework Convention on Climate Change. Bonn: UNFCCC.

UNHCR 1951/1967. Convention and Protocol Relating to the Status of Refugees. Geneva: UNHCR (United Nations High Commissioner for Refugees).

UNICEF. 2018. Bangladesh, Migration Profiles. New York: UNICEF, Available online: https:/esa.un.org/MigGMGProfiles/ indicators/files/Bangladesh.pdf (accessed on 27 November 2018).

Urry, John. 2007. Mobilities. Cambridge: Polity.

van der Velde, Jeannette, Deanna L. Williamson, and Linda D. Ogilvie. 2009. Participatory Action Research: Practical Strategies for Actively Engaging and Maintaining Participation in Immigrant and Refugee Communities. Qualitative Health Research 19: 1293-302. [CrossRef] [PubMed]

Vargas-Silva, Carlos. 2012. Handbook of Research Methods in Migration. Cheltenham: Edward Elgar.

Walsh, Kevin J.E., John L. McBride, Philip J. Klotzbach, Sethurathinam Balachandran, Suzana J. Camargo, Greg Holland, Thomas R. Knutson, James P. Kossin, Tsz-cheung Lee, Adam Sobel, and et al. 2016. Tropical cyclones and climate change. WIREs Climate Change 7: 65-89. [CrossRef]

Watts, Nick, Markus Amann, Nigel Arnell, Sonja Ayeb-Karlsson, Kristine Belesova, Helen Berry, Timothy Bouley, Maxwell Boykoff, Peter Byass, Wenjia Cai, and et al. 2018a. The 2018 report of the Lancet Countdown on health and climate change: Shaping the health of nations for centuries to come. The Lancet 392: 2479-514. [CrossRef]

Watts, Nick, Markus Amann, Sonja Ayeb-Karlsson, Kristine Belesova, Timothy Bouley, Maxwell Boykoff, Peter Byass, Wenjia Cai, Diarmid Campbell-Lendrum, Jonathan Chambers, and et al. 2018b. The Lancet Countdown on health and climate change: From 25 years of inaction to a global transformation for public health. The Lancet 391: 581-630. [CrossRef]

World Bank. 2018. Groundswell: Preparing for Internal Climate Migration. Washington: World Bank. 
World Commission on Dams. 2000. Dams and Development: A New Framework for Decision-Making. London: Earthscan. Wyett, Kelly. 2014. Escaping a Rising Tide: Sea Level Rise and Migration in Kiribati. Asia E Pacific Policy Studies 1: 171-85. [CrossRef]

Yates, Marissa L., Gonéri Le Cozannet, Manuel Garcin, Emilie Salaï, and Patrice Walker. 2013. Multidecadal atoll shoreline change on Manihi and Manuae, French Polynesia. Journal of Coastal Research 29: 870-82. [CrossRef] 